\title{
L'ingénieur, moteur de l'innovation. Un siècle de formation d'ingénieurs à Grenoble
}

Éric Robert, sous la direction de Roger Moret. Institut national polytechnique de Grenoble, Les Éditions des Vignes et l'éditeur, Grenoble, 2001

Yves Bouvier

\section{(2) OpenEdition}

\section{Journals}

Édition électronique

URL : https://journals.openedition.org/histoire-cnrs/398

DOI : 10.4000/histoire-cnrs.398

ISSN : 1955-2408

Éditeur

CNRS Éditions

Édition imprimée

Date de publication : 5 mai 2002

ISBN : 978-2-271-05926-0

ISSN : $1298-9800$

\section{Référence électronique}

Yves Bouvier, «L'ingénieur, moteur de l'innovation. Un siècle de formation d'ingénieurs à Grenoble », La revue pour l'histoire du CNRS [En ligne], 6 | 2002, mis en ligne le 06 mars 2006, consulté le 20 mai 2021. URL : http://journals.openedition.org/histoire-cnrs/398; DOI : https://doi.org/10.4000/histoire-cnrs. 398

Ce document a été généré automatiquement le 20 mai 2021.

Comité pour l'histoire du CNRS 


\section{L'ingénieur, moteur de l'innovation. Un siècle de formation d'ingénieurs à Grenoble}

Éric Robert, sous la direction de Roger Moret. Institut national polytechnique de Grenoble, Les Éditions des Vignes et l'éditeur, Grenoble, 2001

\section{Yves Bouvier}

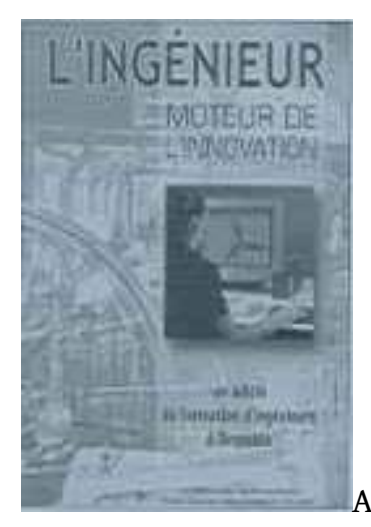

Au pays de la « houille blanche », la demande en techniciens et ingénieurs qualifiés en électricité se fait pressante à la fin du XIX ${ }^{\mathrm{e}}$ siècle. Fortement dépendantes des particularités régionales que sont les demandes en mécanique et en hydraulique, les écoles grenobloises d'ingénieurs ont dispensé des enseignements résolument tournés vers la satisfaction de l'industrie locale. En ce début du XX $\mathrm{XX}^{\mathrm{e}}$ siècle, fortes de leur haute technicité, elles rayonnent néanmoins bien au-delà du Dauphiné. L'ambitieux projet de Paul Janet, professeur en charge d'un cours d'électricité dès 1892, s'ancre en effet davantage dans les savoir-faire que dans la recherche théorique, permettant ainsi non seulement d'accompagner le développement régional mais de fournir toute une génération d'ingénieurs à l'ensemble de l'industrie électrotechnique française. Joseph Pionchon, fondateur et premier directeur de l'Institut d'électrotechnique de Grenoble en 1900, saura être à l'écoute des industriels locaux pour diversifier les études tout en privilégiant l'approche technique aux enseignements 
théoriques de haut niveau. Il ne s'agit pas d concurrencer Polytechnique ou Centrale mais de remplir une fonction intermédiaire entre le technicien et le dirigeant, celle de l'ingénieur. L'électrochimie et l'électrométallurgie, mais aussi la papeterie, témoignent de cette volonté de diversifier les formations au rythme de l'évolution industrielle régionale. Cette extension des activités enseignées se traduit, en 1913, par l'adoption officielle du nom de l'Institut polytechnique de Grenoble (IPG). Néanmoins, la pierre angulaire de l'institution, celle qui fonde sa réputation, reste bien l'hydraulique, et ce jusqu'à la Seconde Guerre mondiale. Le dynamisme des entrepreneurs régionaux facilite, en retour, la réputation des ingénieurs sortis de l'IPG.

1 Il faut toutefois attendre "l'ouverture scientifique » du second après-guerre pour que la formation d'ingénieur s'autonomise véritablement de celle du technicien et pour que Grenoble accueille enfin de véritables laboratoires de recherche. Ceux-ci, avec en particulier le laboratoire du CEA, accompagnent la réorientation des études vers les recherches nucléaires (1955), les mathématiques (1960) et la physique. Sans abandonner les courants forts, le paysage grenoblois s'enrichit de l'École d'ingénieurs électroniciens en 1957. Au cours de cette période, des liens étroits sont tissés entre l'Université, les laboratoires et les industriels nationaux. La figure de Louis Néel, prix Nobel, s'impose pour définir ces orientations dans une recherche en pleine évolution: l'arbitrage n'est plus entre le technicien et l'ingénieur mais entre l'ingénieur et le chercheur. Grâce à ces laboratoires, les écoles grenobloises dépassent rapidement le cadre régional et s'affirment comme des écoles de premier plan au niveau national. Conséquence de l'éclatement du système universitaire en 1968, les écoles d'ingénieurs sont regroupées dans un institut national polytechnique de Grenoble (INPG) en 1969. Fondées sur leurs liens avec la recherche industrielle, les écoles grenobloises attirent les étudiants et valorisent le caractère cumulatif des recherches. Au temps de l'électronique, la capitale de la " houille blanche » attire plus que jamais les entreprises des technologies de pointe.

2 On regrettera que les liens institutionnels avec d'autres écoles, d'autres universités, d'autres laboratoires, n'aient pas été davantage mis en valeur. De même, l'inscription de la recherche grenobloise dans l'espace régional, national et mondial aurait pu être évoquée. En revanche, les liens constants avec les industriels sont sans cesse soulignés avec précision. Ce bel ouvrage, richement illustré, présente ainsi une réflexion de fond sur les ingénieurs à travers la configuration grenobloise. Accompagnée de témoignages nombreux couvrant tous les domaines d'une institution universitaire, cette étude nous plonge non seulement au cœur de l'innovation, mais au cœur de la réussite grenobloise.

\section{AUTEUR}

\section{YVES BOUVIER}

Allocataire-moniteur à l'université de Paris IV-Sorbonne 